$01,04,12$

\title{
Электронные состояния наноструктурированных систем: титан и диоксид циркония
}

\author{
(C) В.Г. Заводинский \\ Институт материаловедения ДВО РАН, \\ Хабаровск, Россия \\ E-mail: vzavod@mail.ru
}

(Поступила в Редакцию 22 марта 2018 г.

В окончательной редакции 30 марта 2018 г.)

\begin{abstract}
Методом теории функционала плотности с использованием псевдопотенциалов исследованы электронные состояния наночастиц и наноструктурных систем: цепочек, пленок и трехмерных наносистем титана и диоксида циркония. Показано, что все изученные наносистемы титана имеют плотность электронных состояний (ПЭС) металлического типа, а наносистемы диоксида циркония демонстрируют диэлектрическую энергетическую щель в окрестностях уровня Ферми. Плотность состояний наноструктурного титана близка по форме к ПЭС монокристалла, но имеет более гладкий вид за счет разупорядоченности расположения атомов. Ширина запрещенной зоны диоксида циркония в наноструктурном состоянии уменьшена по сравнению с соответствующей величиной в кристаллическом $\mathrm{ZrO}_{2}$ : по-видимому, из-за неполной насыщенности ионных связей.
\end{abstract}

DOI: 10.21883/FTT.2018.10.46509.076

\section{1. Введение}

Известно, что электронная структура наночастиц (особенно малых) существенно отличается от электронной структуры массивных материалов. В первую очередь эти отличия определяются размерными эффектами, приводящими к дискретизации электронных состояний и к увеличению роли поверхности. Другой важный эффект, влияющий на электронную структуру, можно назвать фазовым, поскольку он связан с переходом вещества в новое фазовое состояние (по сути, даже в целый спектр новых фазовых состояний). Наиболее известен в этом плане переход углерода в состояние фуллеренов и нанотрубок. К настоящему времени такие наночастичные фазы для многих материалов достаточно хорошо изучены, в том числе теоретически, и описаны во многих работах. Однако реальные нанотехнологии зачастую связаны с использованием не отдельных наночастиц, а их комплексов - одномерных цепочек, двумерных пленок и покрытий, а также трехмерных наноструктурных материалов, каковые формируются, например, в процессах химического синтеза, магнетронного распыления, порошковой металлургии и т. п. [1-4].

Эти материалы обладают удивительными, часто неожиданными качествами. В частности, в аморфном диоксиде циркония обнаруживаются диэлектрические свойства, близкие к свойствам монокристаллического состояния [4]. В то же время, теоретическому изучению таких систем посвящено все еще недостаточно внимания. Например, нам известна лишь одна работа, посвященная моделированию наноструктурного диоксида циркония [5], работ же по моделированию наноструктурных металлов нет вовсе.

В настоящей работе производится сравнительный анализ особенностей электронных состояний металла и диэлектрика при их переходе в наноструктурированное состояние, сопоставляются электронные структуры нульмерных систем (наночастицы), одномерных (бесконечные цепочки), двумерных (пленки) и трехмерных (объемные системы). В качестве металла выбран титан, как широко распространенный материал для современного машиностроения и медицинских применений, а в качестве диэлектрика взят диоксид циркония, покрытия и изделия из которого активно используются в самых различных областях техники, электроники и химических технологий.

\section{2. Методика расчетов}

Для вычисления полной энергии и электронной структуры был применен широко известный пакет программ FHI96md [6], который базируется на теории функционала электронной плотности $[7,8]$, методе псевдопотенциала $[9,10]$ и использует базис плоских волн. В данной работе использованы псевдопотенциалы $\mathrm{Ti}, \mathrm{Zr}$ и $\mathrm{O}$, построенные с помощью пакета FHI98PP [11] и протестированные ранее $[5,12,13]$ с помощью процедуры нахождения равновесных параметров решеток и объемного упругого модуля диоксида титана и диоксида циркония, а также на предмет отсутствия ложных локализованных состояний (ghost states).

Во всех случаях вычисления проводились в приближении обобщенной градиентной поправки (GGA) [14] и проводилась оптимизация атомной геометрии; энергия обрезания набора плоских волн составляла $40 \mathrm{Ry}$. При моделировании использовались наборы специальных $k$-точек с весами ш в зоне Бриллюэна, описанные ранее [15-17]. 
Для титана

$$
\begin{aligned}
& k_{1}=(1 / 8,1 / 8,1 / 8), w_{1}=1 / 16, \\
& k_{2}=(3 / 8,1 / 8,1 / 8), w_{2}=3 / 16, \\
& k_{3}=(3 / 8,3 / 8,1 / 8), w_{3}=3 / 16, \\
& k_{4}=(3 / 8,3 / 8,3 / 8), w_{4}=1 / 16, \\
& k_{5}=(5 / 8,1 / 8,1 / 8), w_{5}=3 / 16, \\
& k_{6}=(5 / 8,3 / 8,1 / 8), w_{6}=3 / 16, \\
& k_{7}=(5 / 8,3 / 8,3 / 8), w_{7}=1 / 16, \\
& k_{8}=(7 / 8,1 / 8,1 / 8), w_{8}=1 / 16 .
\end{aligned}
$$

Для диоксида циркония

$$
\begin{aligned}
& k_{1}=(3 / 4,1 / 4,1 / 4), w_{1}=3 / 4, \\
& k_{2}=(1 / 4,1 / 4,1 / 4), w_{2}=1 / 4 .
\end{aligned}
$$

За основу изучения наноструктурного состояния титана взята наночастица $\mathrm{Ti}_{9}$, имеющая вид объемноцентрированного куба [18]. В процессе оптимизации форма частицы отклонялась от формы идеального куба так, что длины его сторон имели разброс от 2.79 до $3.0 \AA$ А. Общая схема наноструктурных систем титана, исследованных в данной работе, представлена на рис. 1. Расчеты проводились в следующей последовательности.

1. Для частицы $\mathrm{Ti}_{9}$ находилась равновесная полная энергия и вычислялась плотность электронных состояний (ПЭС).

2. К частице $\mathrm{Ti}_{9}$ присоединялась такая же частица $\mathrm{Ti}_{9}^{*}$, повернутая на $45^{\circ}$ (рис. $1, a$ ). Таким образом, обеспечивалась приближенная к реальности (неплоская) граница между наночастицами, т.е. конструировался нанокомплекс $\mathrm{Ti}_{18}=\mathrm{Ti}_{9}+\mathrm{Ti}_{9}^{*}$. Путем транслирования нанокомплекса $\mathrm{Ti}_{18}$ моделировалась бесконечная наноцепочка с периодом $11.75 \AA$ в направлении $X$.

3. Из наноцепочек с ячейкой $\mathrm{Ti}_{18}$ конструировался и исследовался нанослой (нанопленка), лежащий в плоскости $X Y$. Конструирование производилось таким образом, чтобы частицы $\mathrm{Ti}_{9}$ граничили с частицами $\mathrm{Ti}_{9}^{*}$ (рис. $\left.1, b\right)$. Двумерная ячейка нанопленки содержала 36 атомов титана $\left(\mathrm{Ti}_{36}\right)$.

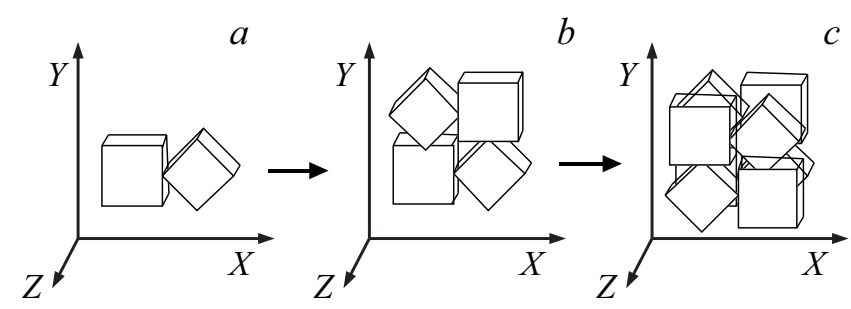

Рис. 1. Схемы устройства ячеек изучаемых наносистем титана. $a-$ ячейка наноцепочки $\left(\mathrm{Ti}_{18}=\mathrm{Ti}_{9}+\mathrm{Ti}_{9}^{*}\right) ; b-$ ячейка двумерной нанопленки $\left(\mathrm{Ti}_{36}\right) ; c-$ ячейка трехмерного наноструктурного материала $\left(\mathrm{Ti}_{72}\right)$.

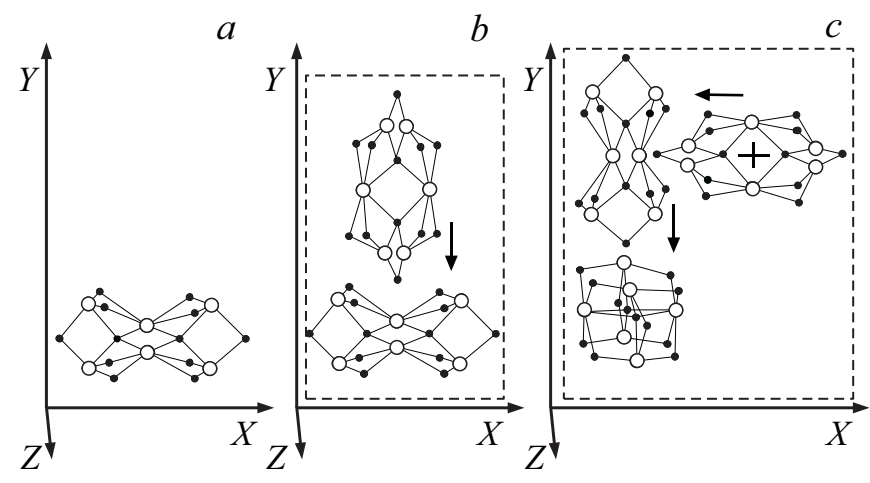

Рис. 2. Схемы строения наносистем диоксида циркония. $a$ - наночастица $\mathrm{Zr}_{6} \mathrm{O}_{12} ; b-$ ячейка $\mathrm{Zr}_{12} \mathrm{O}_{24}$ наноцепочки, направленной по оси $Y$; $c$ - ячейка $\mathrm{Zr}_{18} \mathrm{O}_{36}$ нанопленки, расположенной в плоскости $X Y$. Для наглядности частицы $\mathrm{Zr}_{6} \mathrm{O}_{12}$ на панелях $B$ и $C$ изображены в отдалении друг от друга. На панели $C$ символом + обозначено место присоединения комплекса из двух частиц $\mathrm{Zr}_{6} \mathrm{O}_{12}$, соединенных так, как показано на панели $B$, для формирования ячейки трехмерного наноструктурного диоксида циркония с ячейкой $\mathrm{Zr}_{30} \mathrm{O}_{60}$.

4. На базе двумерной ячейки нанопленки $\mathrm{Ti}_{36}$ конструировалась трехмерная ячейка массивного наноструктурного титана $\mathrm{Ti}_{72}$, в котором каждая наночастица $\mathrm{Ti}_{9}$ окружена частицами $\mathrm{Ti}_{9}^{*}$ (рис. $1, c$ ).

5. Для сравнения проводился также расчет электронной структуры объемного титана.

Для исследования наноструктурного диоксида циркония взята за основу наночастица $\mathrm{Zr}_{6} \mathrm{O}_{12}$, описанная и исследованная ранее [19]. Схема ее устройства изображена на рис. 2, $a$. Отметим, что структура частицы $\mathrm{Zr}_{6} \mathrm{O}_{12}$ такова, что она позволяет частицам соединяться друг с другом без преодоления энергетических барьеров (наподобие деталям популярного конструктора LEGO), достигая при этом минимума полной энергии. (Возможность самосборки наноструктурного диоксида циркония указана в работе [20].) На этом же рис. 2 изображены схемы формирования наноструктурных систем диоксида циркония из наночастиц $\mathrm{Zr}_{6} \mathrm{O}_{12}$ : одномерной наноцепочки (рис. $2, b)$ и двумерного нанослоя (пленки) (рис. 2,c). Строение трехмерной наносистемы не показано, так как ее строение трудно визуализировать на двумерном рисунке.

Последовательность исследования систем диоксида циркония примерно такая же, как и в случае титана.

1. Для частицы $\mathrm{Zr}_{6} \mathrm{O}_{12}$ находилась равновесная полная энергия и вычислялась плотность электронных состояний (ПЭС).

2. К частице $\mathrm{Zr}_{6} \mathrm{O}_{12}$ присоединялась такая же частица $\mathrm{Zr}_{6} \mathrm{O}_{12}$, повернутая на $90^{\circ}$. градусов. То есть, конструировался нанокомплекс $\mathrm{Zr}_{12} \mathrm{O}_{24}=\mathrm{Zr}_{6} \mathrm{O}_{12}+\mathrm{Zr}_{6} \mathrm{O}_{12}$. Путем транслирования нанокомплекса $\mathrm{Zr}_{12} \mathrm{O}_{24}$ моделировалась одномерная цепочка с периодом около $12 \AA$ в направлении $Y$. 
3. Путем добавления к нанокомплексу $\mathrm{Zr}_{12} \mathrm{O}_{24}$ еще одной частицы $\mathrm{Zr}_{6} \mathrm{O}_{12}$ конструировалась и исследовалась двумерная нанопленка, лежащая в плоскости $X Y$. Двумерная ячейка нанопленки имела состав $\mathrm{Zr}_{18} \mathrm{O}_{36}$.

4. На базе двумерной ячейки нанопленки $\mathrm{Zr}_{18} \mathrm{O}_{36}$ конструировалась трехмерная ячейка массивного наноструктурного диоксида циркония путем добавления еще двух частиц $\mathrm{Zr}_{6} \mathrm{O}_{12}$. Трехмерная ячейка имела форму куба и состав $\mathrm{Zr}_{30} \mathrm{O}_{60}$.

5. Для сравнения проводился расчет электронной структуры объемного кубического диоксида циркония.

\section{3. Результаты и обсуждение}

3.1. Титан. На рис. 3 представлены результаты расчета ПЭС для различных систем титана, на рис. 4 для сравнения приведены данные других авторов [21-23].

Анализ рис. 3 и 4 показывает, что полной идентичности ПЭС для одного и того же объемного материала, полученных разными авторами, нет. Сказывается разница методов и использованных при этом параметров расчета. Однако общие закономерности формы ПЭС при этом сохраняются. Наш результат (рис. $3, a$ ) отличается от результатов других авторов (рис. 4, $a, b$ ) примерно настолько, насколько и они отличаются друг от друга, т.е. он вполне удовлетворительно согласуется с обоими опубликованными.

Рассчитанная нами ПЭС для наночастицы $\mathrm{Ti}_{9}$ (рис. $3, b$ ) тоже качественно согласуется с ПЭС, приведенной на (рис. $4, c)$. Имеется лишь некоторая количественная разница в положении пиков, но она вполне объяснима, поскольку и размеры кластеров и их геометрия отличаются. К сожалению, нам не удалось найти опубликованных результатов для кластера $\mathrm{Ti}_{9}$, поэтому пришлось использовать данные для $\mathrm{Ti}_{13}$.

Основной интерес при рассмотрения рис. 3 вызывает анализ изменений, которые претерпевают ПЭС при переходе наноструктрных систем от нульмерной (наночастица) к одномерной (цепочка), двумерной (пленка) и трехмерной (объем) системам. У наночастицы (рис. $3, b$ ) мы видим в валентной части четко выраженные пики с максимумами при $-0.3,-1.1,-1.8$ и $-3.4 \mathrm{eV}$. Уже в наноцепочке, состоящей из таких же частиц, но разупорядоченных между собой, эти пики расщепляются, распадаются и несколько сдвигаются в сторону отрицательных энергий. Аналогичное расщепление пиков мы видим и в состояниях проводимости, лежащих выше уровня Ферми. Переход к двумерной системе (нанопленке) (рис. $3, e$ ) демонстрирует продолжение этого процесса. Электронные состояний еще более расщепляются, что приводит к их смешиванию и внешне проявляется как сглаживание формы ПЭС. Это сглаживание усиливается в трехмерной наноструктурированной системе (рис. $3, f$ ), где атомы металла, в силу малого масштаба наноструктуры, переходят в почти аморфное состояние. Общее очертание ПЭС такой системы близко к форме

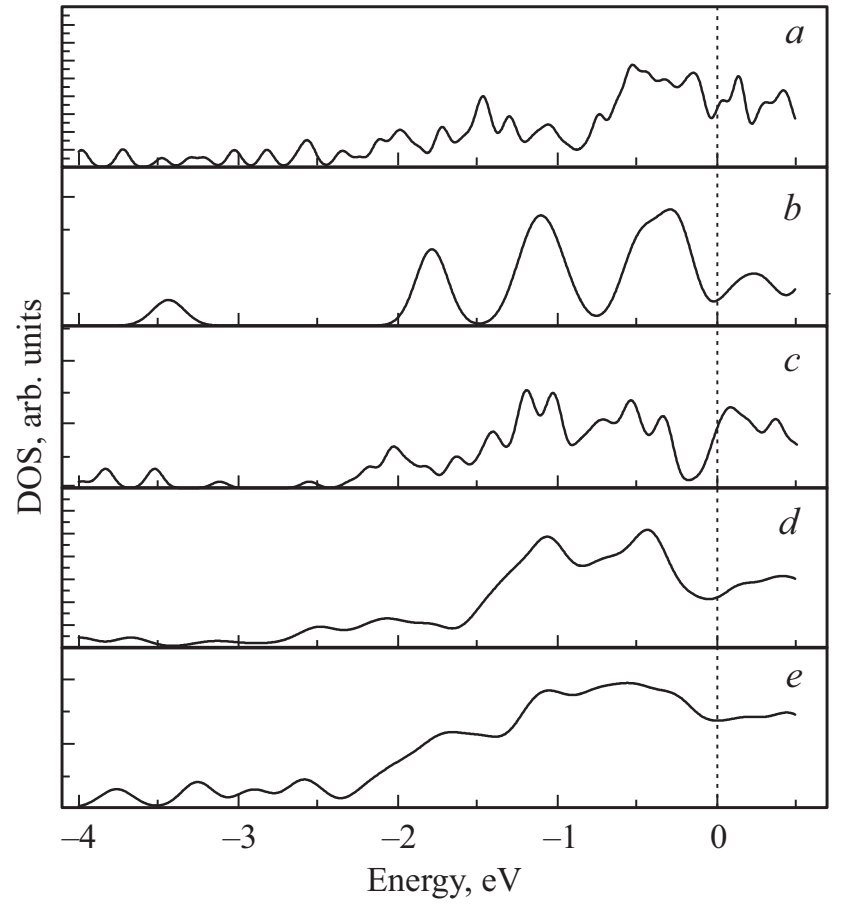

Рис. 3. Плотность состояний изученных систем титана. $a$ - объемный монокристаллический титан; $b-$ наночастица $\mathrm{Ti}_{18} ; c-$ наноструктурная цепочка с ячейкой $\mathrm{Ti}_{18} ; d-$ наноструктурная пленка с ячейкой $\mathrm{Ti}_{36} ; e-$ наноструктурный объемный материал с ячейкой $\mathrm{Ti}_{72}$. Вертикальная пунктирная линия обозначает уровень Ферми.

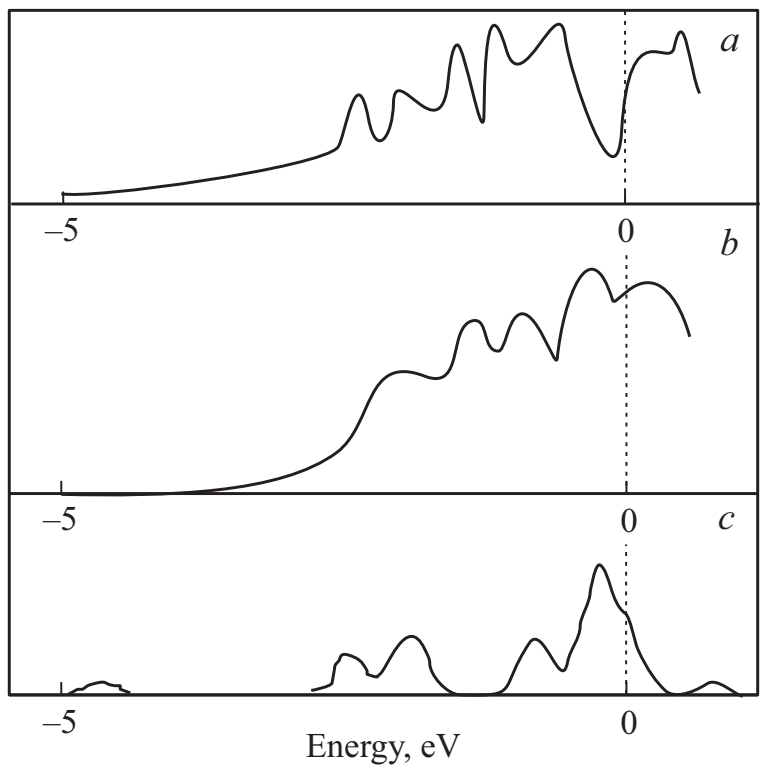

Рис. 4. Опубликованные ПЭС: $a$ - объемный bсс-титан [21], $b$ - объемный bсc-титан [22], $c$ - наночастица $\mathrm{Ti}_{13}$ [23].

ПЭС монокристалла (рис. $3, a$ ), однако в ней отсутствует тонкая структура, характерная для упорядоченного расположения атомов в кристалле. По-видимому, тонкая структура проявилась бы в системе, состоящей из более крупных наночастиц. 
3.2. Диоксид циркония. На рис. 5 представлены результаты расчета ПЭС наноструктурного диоксида циркония, а на рис. 6 приведены данные других авторов.

Как и в предыдущем разделе, анализ рисунков показывает, что полной идентичности ПЭС для одного и того же объемного диоксида циркония, полученных разными авторами (рис. $6, a, b)$, нет, но налицо общие закономерности формы ПЭС: сходные группы пиков в тех же областях занятых и свободных состояний, примерно одинаковая ширина запрещенной зоны $(3.28 \mathrm{eV}$ [24], $3.32 \mathrm{eV}$ [25]. Наш результат (рис. 5, $a$ ) вполне удовлетворительно согласуется с этими опубликованными.

К сожалению, мы не нашли в литературе опубликованных изображений ПЭС для наночастиц диоксида циркония (кроме принадлежащих автору данной статьи). Имеются лишь некоторые сведения о величине

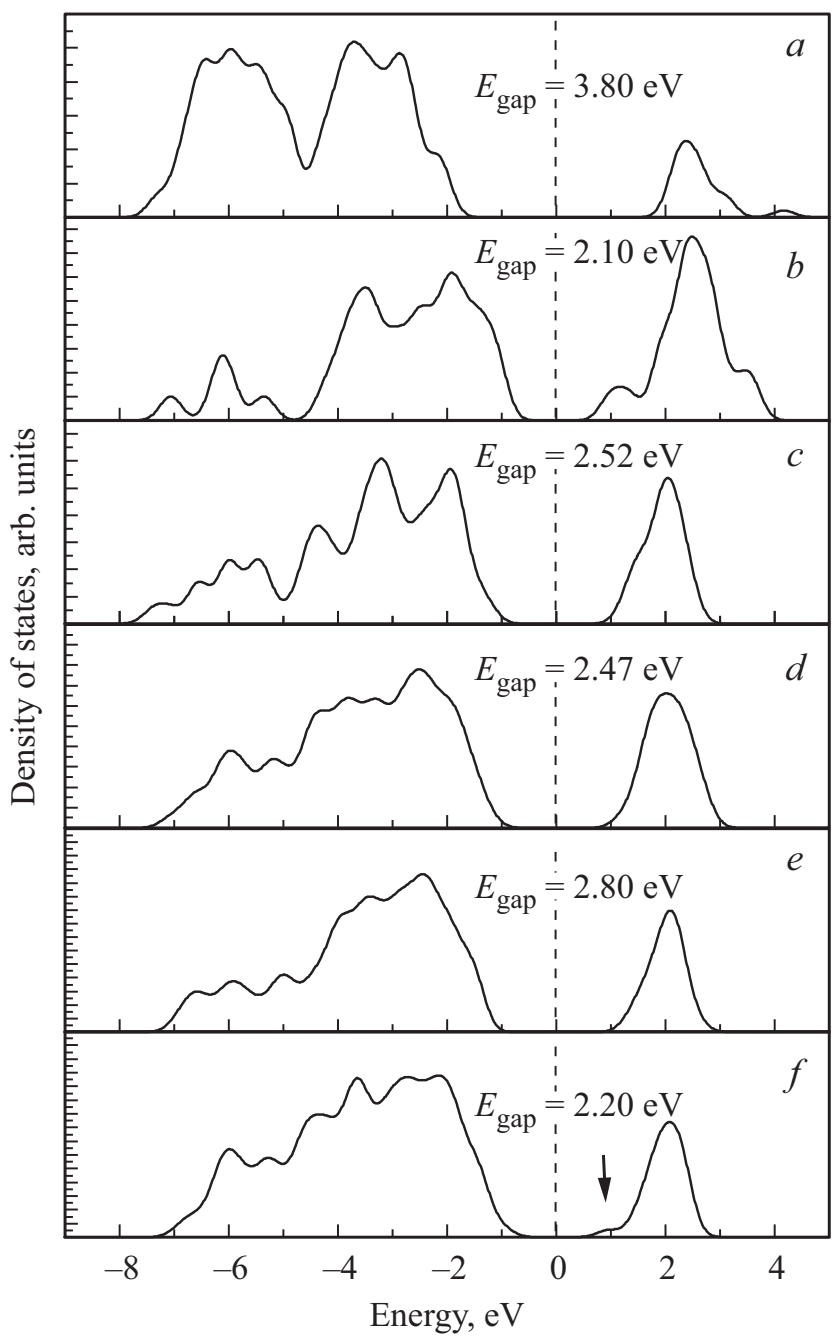

Рис. 5. Плотность состояний изученных систем диоксида циркония. $a-$ объемный монокристаллический $\mathrm{ZrO}_{2} ; b-$ наночастица $\mathrm{Zr}_{6} \mathrm{O}_{12} ; c-$ наноструктурная цепочка с ячейкой $\mathrm{Zr}_{12} \mathrm{O}_{24} ; d-$ двумерная наноструктурная система с ячейкой $\mathrm{Zr}_{18} \mathrm{O}_{36} ; e-$ трехмерный наноструктурный материал с ячейкой $\mathrm{Zr}_{30} \mathrm{O}_{60}$. Вертикальная пунктирная линия обозначает уровень Ферми.

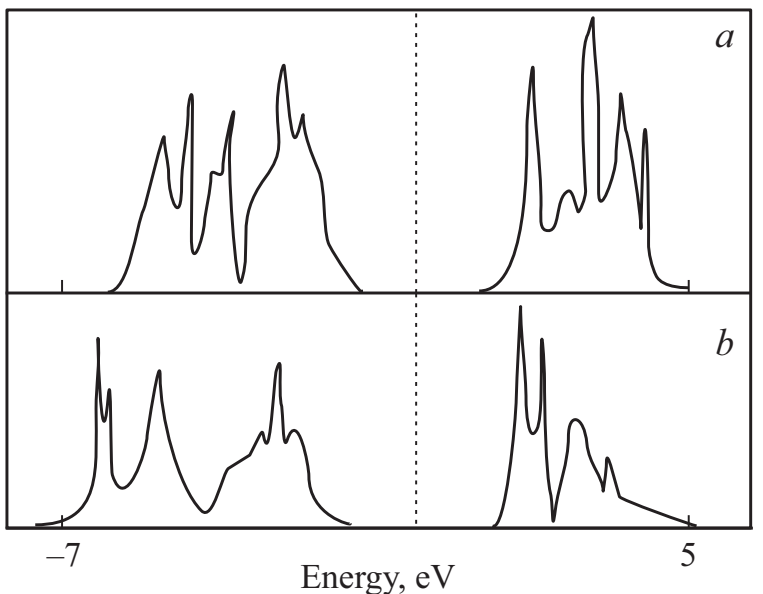

Рис. 6. Опубликованные ПЭС: $a$ - объемный $c-\mathrm{ZrO}_{2}$ [24], $b$ - объемный $c-\mathrm{ZrO}_{2}[25]$.

энергетической щели. При этом отмечается, что связь величины энергетической щели с размерами наночастиц диоксида циркония при малых размерах частиц (до $\mathrm{Zr}_{8} \mathrm{O}_{16}$ ) неоднозначна и немонотонна [26,27], однако для более крупных частиц (начиная с $\mathrm{Zr}_{16} \mathrm{O}_{32}$ ) щель увеличивается с ростом частицы [28].

ПЭС для $\mathrm{Zr}_{6} \mathrm{O}_{12}$, приведенная на (рис. 5,b), демонстрирует щель величиной $2.1 \mathrm{eV}$, в то время как для объемного материала (рис. 5, $a$ ) получена величина $3.8 \mathrm{eV}$. В более ранней работе автора [5], где использованы несколько иные параметры вычислений, приведены величины $2.5 \mathrm{eV}$ для $\mathrm{Zr}_{6} \mathrm{O}_{12}$ и $3.5 \mathrm{eV}$ для кристалла.

Спектр валентных состояний наночастицы $\mathrm{Zr}_{6} \mathrm{O}_{12}$, как и спектр ПЭС объемного диоксида циркония, содержит две группы пиков, лежащих в области от -1 до $-8 \mathrm{eV}$. Ширина щели у одномерной наносистемы (рис. 5, c) возрастает до $2.52 \mathrm{eV}$, несколько падает до $2.47 \mathrm{eV}$ в двумерной системе (рис. $5, d$ ) и существенно уменьшается до $2.2 \mathrm{eV}$ в трехмерной наноструктурной системе (рис. 5,e), что, по-видимому, обусловлено неполным насыщением ионных связей и на картине ПЭС отражается в появлении наплыва в начале области свободных состояний, помеченного на рис. 5, е стрелкой. Уменьшение щели в трехмерной наноструктурной системе коррелирует с результатами работы [5], в которой для наноструктурного диоксида циркония с иной геометрией, чем в текущей работе, была получена величина энергетической щели, равная $2.6 \mathrm{eV}$, в то время как для объемного $\mathrm{ZrO}_{2}$ она оказалась равной $3.5 \mathrm{eV}$.

Необходимо подчеркнуть, что рассмотренная в данной работе трехмерная наноструктурная система диоксида циркония построена специальным, упорядоченным образом и не может рассматриваться как модель аморфного $\mathrm{ZrO}_{2}$, подобного изученному экспериментально в работе [4], где была обнаружена энергетическая щель величиной $4.7 \mathrm{eV}$. Теоретическому исследованию аморфного диоксида циркония следует посвятить отдельную работу. 


\section{4. Выводы}

Проведенные на примере титана и диоксида циркония модельные исследования наноструктурных систем металла и диэлектрика позволяют сделать следующие выводы.

1. Наноструктурные системы титана имеют высокую плотность состояний на уровне Ферми, а наноструктурные системы диоксида циркония демонстрируют энергетическую щель в окрестностях этого уровня.

2. С увеличением размерности наноструктурных систем титана форма их ПЭС приближается к форме ПЭС у кристаллического титана, но приобретает более размытый вид из-за разупорядоченности расположения атомов.

3. У наноструктурных систем диоксида циркония с ростом их размерности наблюдается уменьшение энергетической щели, при этом форма спектра занятых состояний изменяется несущественно.

Следует заметить, что приведенные в данной работе результаты получены без учета структурных изменений, протекающих в условиях реальных экспериментов и технологических процессов под влиянием повышенной температуры. Однако даже такое упрощенное рассмотрение показывает, что электронная структура как металлических, так и диэлектрических трехмерных наноструктурных систем имеет много общего с электронной структурой объемных (монокристаллических) материалов.

\section{Список литературы}

[1] И.П. Семенова, В.В. Латыш, А.В. Щербаков, Е.Б. Якушина. Рос. нанотех. 3, 9-10, 106 (2008).

[2] И.О. Болотина, В.И. Данилов, А.А. Загуменный. Прикл. мех. тех. физ. 49, 3, 164 (2008).

[3] Л.М. Рудковская, Р.Н. Пшеничный, Т.В. Павленко, А.А. Омельчук. Nanosystems, nanomaterials, nanotechnologies 10, 2, 351 (2012).

[4] V. Gritsenko, D. Gritsenko, S. Shaimeev, V. Aliev, K. Nasyrov, S. Erenburg, V. Tapilin, H. Wong, M.C. Poon, J.H. Lee, J.-W. Lee, C.W. Kim. Microelectron. Eng. 81, 524 (2005).

[5] V.G. Zavodinsky, A.N. Chibisov. J. Physics: Conf. Ser. 29, 173 (2006).

[6] M. Beckstedte, A. Kley, J. Neugebauer, M. Scheffler. Comp. Phys. Commun. 107, 187 (1997).

[7] H. Hohenberg, W. Kohn. Phys. Rev. 136, B864 (1964).

[8] W. Kohn, J.L. Sham. Phys. Rev. 140, A1133 (1965).

[9] D.R. Hamann. Phys. Rev. B 40, 129, 2980 (1989).

[10] N. Troullier, J.L. Martins. Phys. Rev. B 43, 1993 (1991).

[11] M. Fuchs, M. Scheffler. Comp. Phys. Commun. 119, 67 (1999).

[12] В.Г. Заводинский, А.Н. Чибисов. ФТТ 51, 477 (2009).

[13] В.Г. Заводинский. ФТТ 46, 441 (2004).

[14] J.P. Perdew, Y. Wang. Phys. Rev. B 33, 8800 (1986).

[15] H.J. Monkhorst, J.D. Pack. Phys. Rev. B 13, 5188 (1976).

[16] D.J. Chadi. Phys. Rev. B 16, 1746 (1977).

[17] В.Г. Заводинский. Компьютерное моделирование наночастиц и наносистем. Физматлит, М. (2013) 174 с.
[18] M. Salazar-Villanueva, P.H. Hernandez Tejeda, U. Pal, J.F. Rivas-Silva, J.I. Rodriguez Mora, J.A. Ascencio. J. Phys. Chem. A 110, 10274 (2006).

[19] В.Г. Заводинский, А.Н. Чибисов. ФТТ 48, 343 (2006).

[20] Ю. Чжан, В. Чэнь, С. Цзян. Междунар. студ. вестн. 6, (2016). https://www.eduherald.ru/ru/article/view?id=16788

[21] M. Jafari, H. Jamnezhad, L. Nazarzadeh. Iranian J. Sci. Technology A 4, 511 (2012).

[22] Keeyung Lee. J. Kor. Phys. Soc. 45, 2, 333 (2004).

[23] Jijun Zhao, Qi Qiu, Baolin Wang, Jinlan Wang, Guanghou Wang. Solid State Commun. 118, 157 (2001).

[24] S.E. Kulkova, O.N. Muryzhnikova. Phyica B 192284 (1993).

[25] M.G. Mulaudzi. Dissertation. http://hdl.handle.net/10386/1393.

[26] S.M. Woodley, S. Hamad, J.A. Mejı'asb, C.R.A. Catlow. J. Mater. Chem. 16, 1927 (2006).

[27] J. Rui, Z. Yonghong, H. Shiping, W. Peng, T. Pinghui. Chin. J. Chem. 29, 13 (2011).

[28] A.R. Puigdollers, F. Illas, G. Pacchioni. J. Phys. Chem. (2016). DOI: $10.1021 /$ acs.jpcc.5b12185

Редактор Т.Н. Василевская 